\title{
Effect of Layer Sequence on Formation of CdTe Thin Film Prepared by Stacked Elemental Layers
}

\author{
S. H. Moustafa \\ Physics Department, Faculty of Science, Helwan University, Helwan, \\ Cairo, Egypt
}

Three different sequences of $\mathrm{Cd}$ and Te were stacked to prepare polycrystalline CdTe thin films by the effect of annealing. X-ray diffraction analysis was used to characterize the prepared films. Although under some preparation conditions annealed films exhibit traces of Tellurium oxides, films of single polycrystalline CdTe phase have been successfully obtained even with annealing in air as an easy and simple manner. The best condition was sequence of glass $/ \mathrm{Te} / \mathrm{Cd} / \mathrm{Te}$ and annealing at $200^{\circ} \mathrm{C}$ for 30 minutes. The grain size was determined by line profile analysis using WinFit computer program and Fourier analysis. It was proved that film with grains in the nanoscale region can be fabricated using this technique. It was found that the average crystallite size $\approx 9.4 \mathrm{~nm}$ and the cumulative size distribution showed that there are no grains larger than $30 \mathrm{~nm}$. Transmission and reflection for thin film contain only CdTe were measured in the wavelength range 300-2500 $\mathrm{nm}$. Optical energy gap was extracted from the manipulation of transmission and reflection data. The values of energy gaps $(1.5-1.65 \mathrm{eV})$ verify that, the films under consideration are a polycrystalline CdTe films.

\section{Introduction:}

Cadmium Telluride (CdTe) is still considered as one of the most promising polycrystalline materials for producing photovoltaic cells because of its high absorption coefficient $\left(>10^{4} \mathrm{~cm}^{-1}\right)$ and optimum band gap $(1.5 \mathrm{eV})$. CdTe thin films have grown by different techniques: sputtering [1], electrodeposition [2], Vacuum evaporation [3], electrochemical atomic layer epitaxy [4], pulsed laser deposition [5-7] and Close-spaced sublimation [8]. The stacked elemental layer (SEL) is a technique suitable for large area development because of the simplicity of control of deposition parameters and the flexibility in the choice of processing method of the elemental stacks [9-11]. 
This work will deal with the effect of layer sequence and heat treatment (annealing temperature) on the formation of CdTe polycrystalline thin films using stacked layers of $\mathrm{Cd}$ and $\mathrm{Te}$ elements. X-ray diffraction investigation (size/strain analysis) as well as the spectroscopic study (optical gap measurements) will be used to verify the formation of single polycrystalline CdTe phase.

\section{Experimental:}

The layers were deposited by thermal evaporation technique (PVD) using E306A vacuum system. Taking into consideration that the number of atoms in $\mathrm{Te}$ and $\mathrm{Cd}$ layers must be identical, the relation between the thicknesses of elemental layers is specified as $\mathrm{Te} / \mathrm{Cd}=1.53$ [12]. Spec-pure $\mathrm{Cd}(99.999 \%)$ and $\mathrm{Te}(99.9999 \%)$ were evaporated in three different sequences using glass substrates at room temperature. A film thickness monitor (Edwards FTM4, England) was used to control the film deposition rate and to estimate the film thickness. The readings of the monitor were optically calibrated. The three prepared sample sequences were annealed in air, as an easy and simple manner, for 30 minutes at $150,200,250$, and $300^{\circ} \mathrm{C}$.

For the structural investigation, computer controlled X-ray diffractometer with monochromatic $\mathrm{Co}-\mathrm{K}_{\alpha}$ radiation $(\lambda=0.179 \mathrm{~nm})$ was used. In order to cover all the possible diffraction lines of CdTe, the scanning range was $20-70^{\circ}$

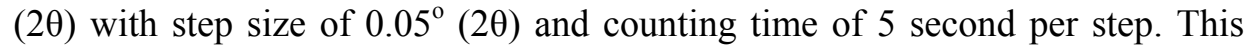
measurable range was chosen because all probable phases of $\mathrm{Cd}$ and $\mathrm{Te}$ lie in that range. Peak fit and data analysis (peak position, integrated intensity and grain size) were accomplished by the WinFit computer program of Krumn [13].

The optical transmittance $\mathrm{T}$, and reflectance $\mathrm{R}$, spectra were recorded at normal light incident in the wavelength range $300-2500 \mathrm{~nm}$, using a double beam spectrophotometer (Type Jasco, V-570, Rerl-1.00-UV-VIS-NIR).

\section{Results and discussion:}

All the prepared films show good adhesion on the glass substrate. Three sequences stacked layers were investigated as follows:

\subsection{Phase Identification:}

A- Glass $(\mathrm{g}) / \mathrm{Cd} / \mathrm{Te}$ sequence:

The XRD diffractograms of the annealed films at different temperatures are shown in Fig. (1). The area under the (111) peak of CdTe is increased with the annealing temperature as depicted in Fig. (2). As the annealing temperature 
ascends, the quantity of CdTe increases and its quality (crystallinity) enhanced. For films annealed at 250 and $300{ }^{\circ} \mathrm{C}$, only single phase of CdTe is present. Other peaks, which are observed in the diffractograms of films that are annealed at temperature of 150 and $200{ }^{\circ} \mathrm{C}$, are mainly related to the $\alpha-\mathrm{TeO}_{3}$ phase.

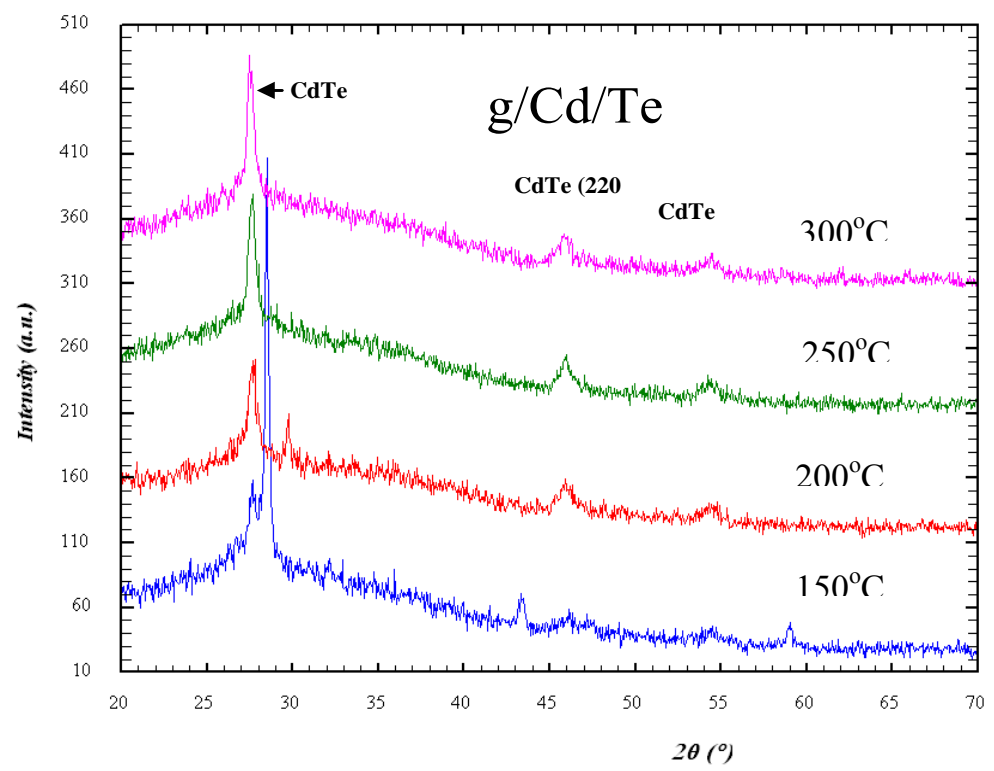

Fig.(1): X-ray diffractograms of $\mathrm{g} / \mathrm{Cd} / \mathrm{Te}$ thin film sequence.

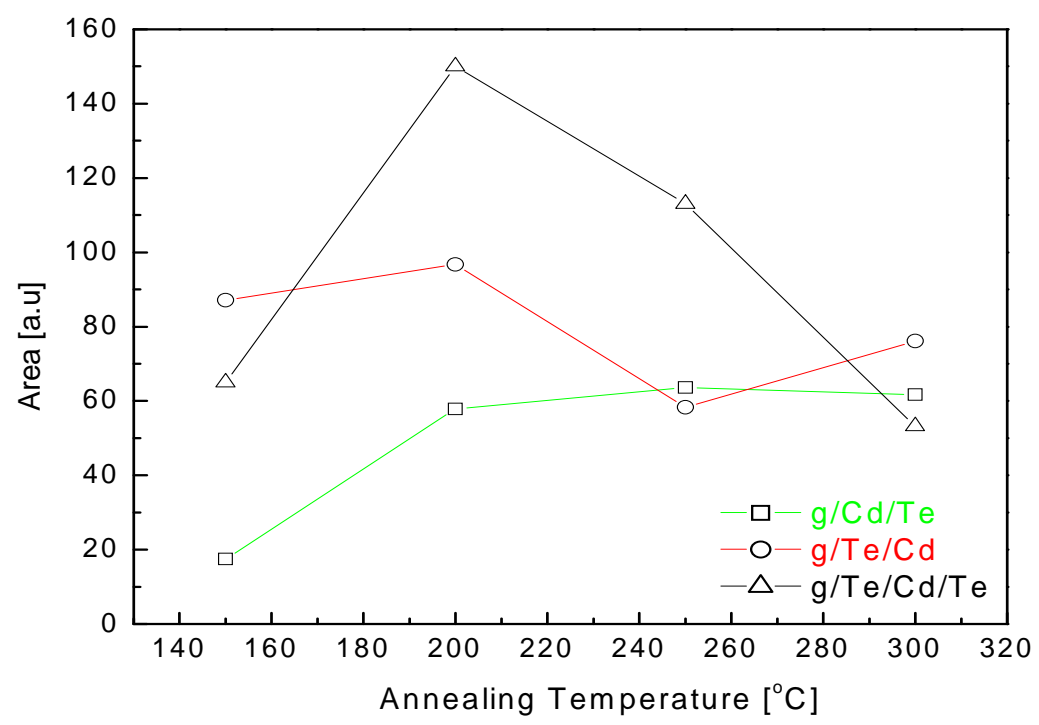

Fig.(2): Change of the area under (111) peak of CdTe with annealed samples for the three sequences. 
B- Glass (g)/Te/Cd sequence:

Figure (3) presents of four diffractograms for annealing at different temperature. At $150^{\circ} \mathrm{C}$ the three strongest CdTe peaks (111), (220) and (311) exist as well as (002) peak of $\mathrm{Cd}$. This attributed to the presence of Cd layer on the top of the film and the low annealing temperature $150^{\circ} \mathrm{C}$ that is not enough to complete the reaction. At 200 and $250^{\circ} \mathrm{C}$, the diffraction patterns show $\mathrm{CdTe}$ peaks beside some traces of tellurium oxide peaks. The best condition in this sequence was achieved at annealing temperature of $300^{\circ} \mathrm{C}$ where only the main CdTe peaks are observed.

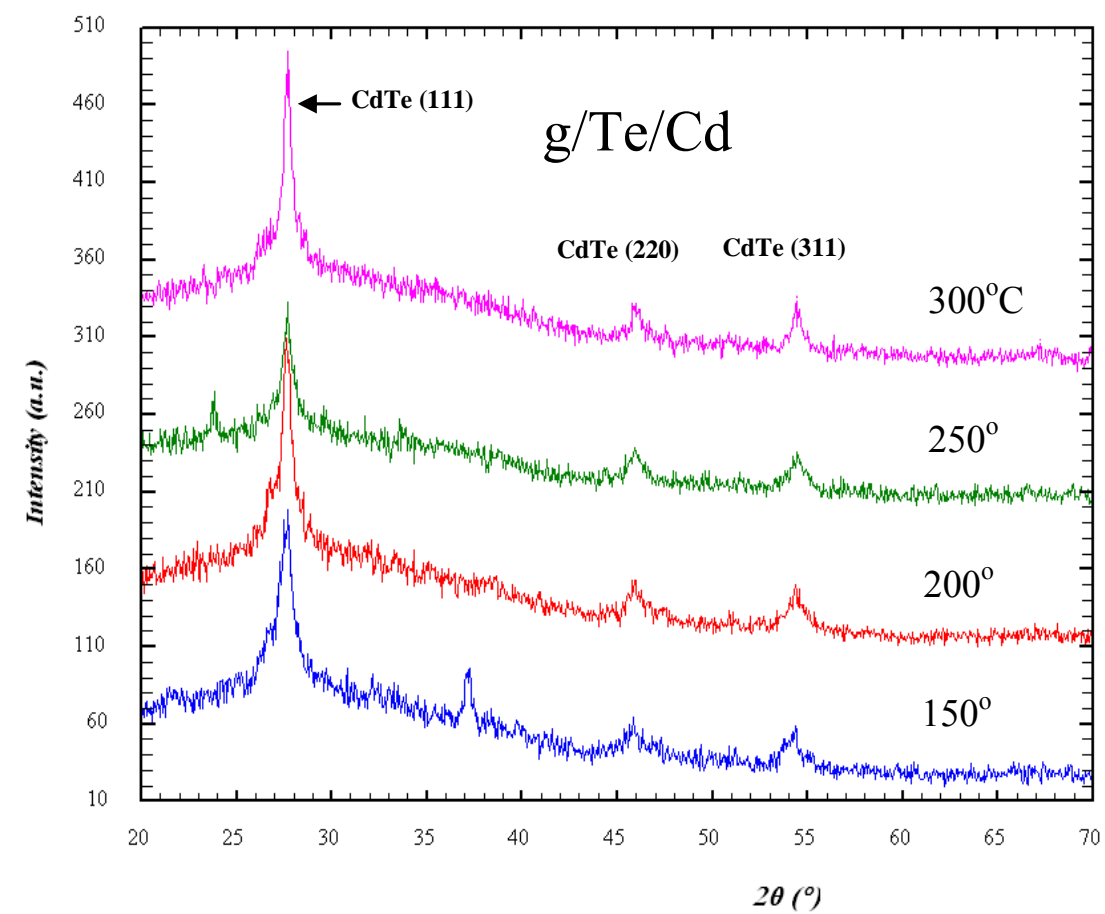

Fig.(3): X-ray diffractograms of $\mathrm{g} / \mathrm{Te} / \mathrm{Cd}$ thin film sequence.

\section{C- Glass (g)/Te/Cd/Te sequence:}

In this sequence, $\mathrm{Cd}$ is sandwiched between two Te layers of equal thickness. X-ray diffractograms of samples annealed at different annealing temperatures are shown in Fig. (4). The change in area of CdTe (111) peak with annealing temperature is shown in Fig. (2). At $200^{\circ} \mathrm{C}$ only the main peaks of $\mathrm{CdTe}$ are present and the maximum value of area under the (111) peak was observed. Weak peaks that are observed in the three other diffractograms mainly related to tellurium oxide phases. 


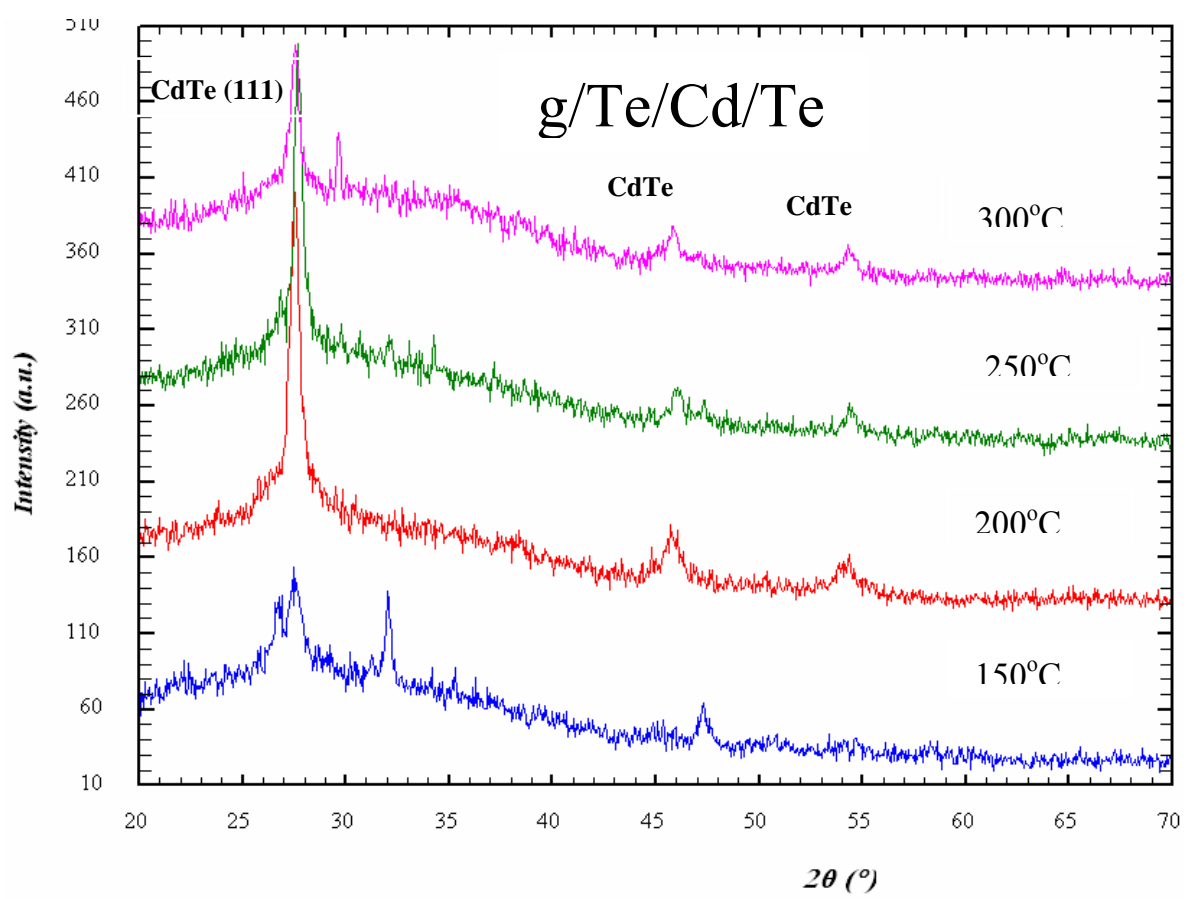

Fig.(4): $\mathrm{X}$-ray diffractograms of $\mathrm{g} / \mathrm{Te} / \mathrm{Cd} / \mathrm{Te}$ thin film sequence.

Tellurium oxide peaks are observed in X-ray patterns because the annealing was carried out in air and the chemical activity of Te is higher than that of Cd. The optimum condition for preparation of single CdTe films can be extracted from the variation of the integrated intensity of CdTe (111) peak as depicted in Fig. (2). It is quite clear that in general the sequence $\mathrm{g} / \mathrm{Te} / \mathrm{Cd} / \mathrm{Te}$ shows the highest intensity. Annealing temperature of $200^{\circ} \mathrm{C}$ is the optimum condition for obtaining single phase of polycrystalline CdTe films.

\subsection{Size/Strain Analysis:}

Grain size and size distribution of the optimum sample were calculated by Fourier analysis using single line approach [14]. The crystallite size was estimated from the (111) diffraction line at $2 \theta \approx 27.53^{\circ}$. Fig. (5) shows the normalized Fourier coefficients $A(L)$ plotted versus the domain size $L=n a_{3}$, normal to the reflecting plane, where $\mathrm{n}$ is the harmonic number and $\mathrm{a}_{3}$ is a length depending on the d-spacing of the reflecting plane. All values of Fourier coefficient $\mathrm{F}(\mathrm{L})$ are normalized $(\mathrm{A}(\mathrm{L})=\mathrm{F}(\mathrm{L}) / \mathrm{F}(0))$ to give $\mathrm{A}(0)=1)$. The steepest part of the linear extrapolation towards $A(L)=0$ yields the mean coherently diffraction domain or the average crystallite size. From the intercept of the straight part with the $\mathrm{x}$-axis an average value of the crystallite size was estimated as $9.4 \mathrm{~nm}$. 


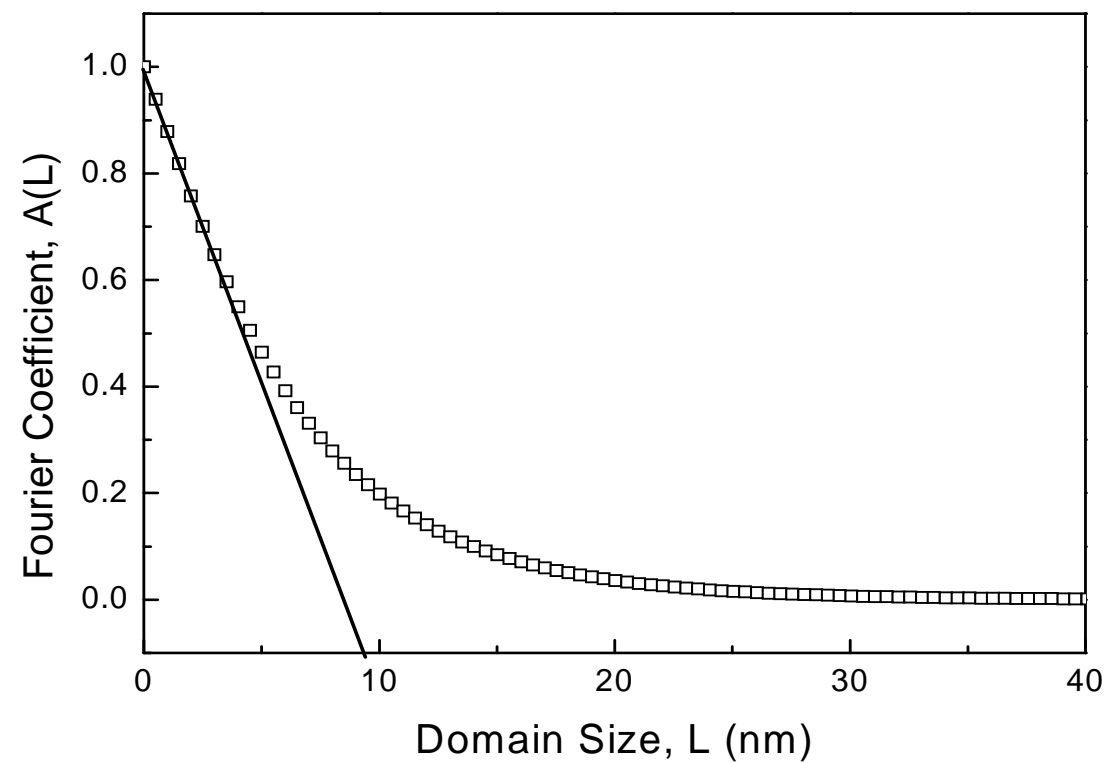

Fig.(5): Plot of normalized Fourier coefficient A(L) versus domain size L.

The cumulative grain size distribution for the first case (\% finer) is illustrated in Fig. (6). It is clear that there is no grain larger than $30 \mathrm{~nm}$. Variation of crystallite size with annealing temperatures was depicted in Fig. (7). An increase of the size was observed as the temperature ascends as a result of grain growth with temperature.

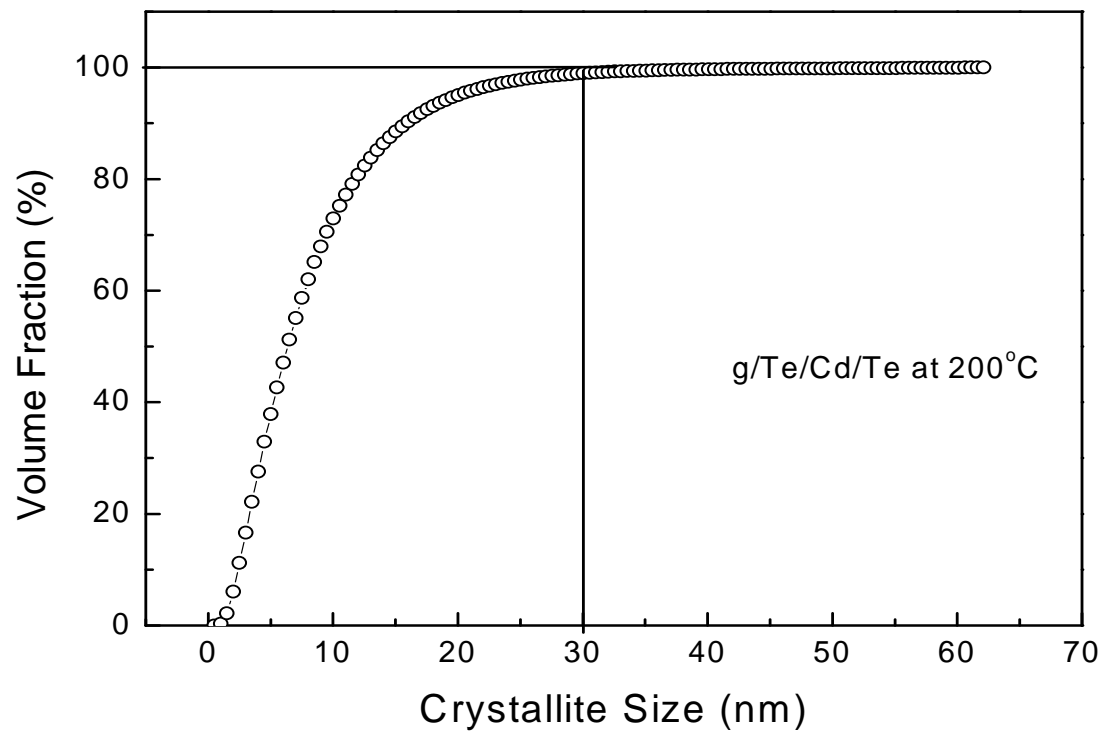

Fig.(6): Cumulated crystallite size distributions for the $\mathrm{g} / \mathrm{Te} / \mathrm{Cd} / \mathrm{Te}$ sample annealed at $200^{\circ} \mathrm{C}$. 


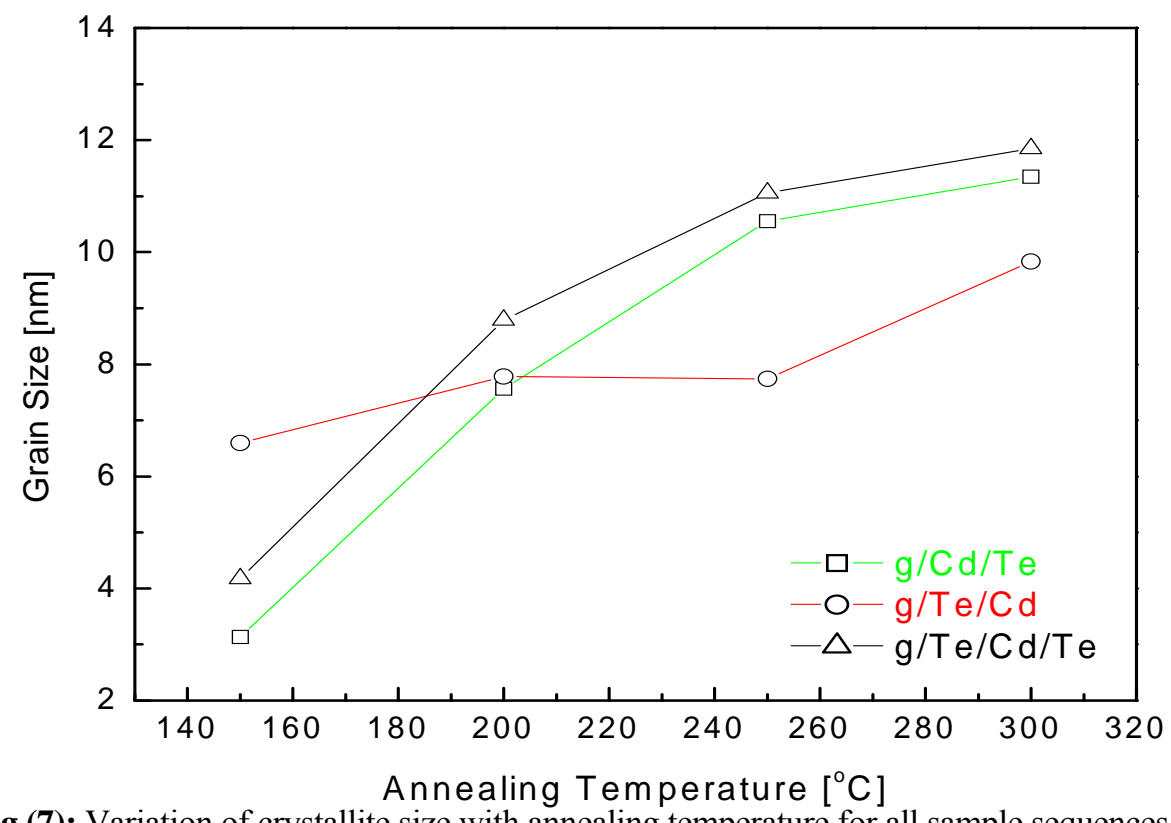

Fig.(7): Variation of crystallite size with annealing temperature for all sample sequences.

There is no considerable change in the residual internal strain between the three different sequences or at different annealing temperature. Variation of distortion is shown in Fig. (8). Almost the films are strain free of only about $0.5 \%$.

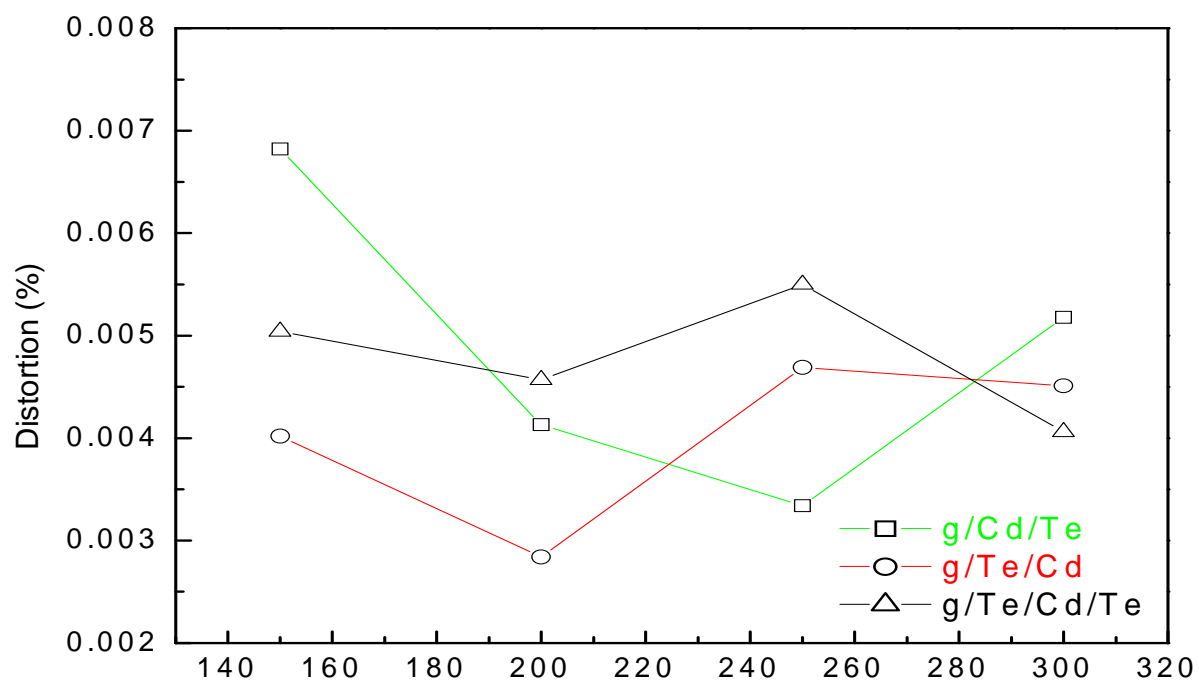

Annealing Temperature $\left[{ }^{\circ} \mathrm{C}\right]$

Fig.(8): Variation of internal strain with annealing temperature for all sample sequences. 


\subsection{Optical Investigation:}

The spectral behaviour of the transmittance, $T(\lambda)$, and reflectance, $R(\lambda)$, at normal incidence for the best sample of each of the three sequences are shown in Fig. (9) in the wavelength range 300-2500 $\mathrm{nm}$. The appearance of interference maxima and minima at the same wavelength above the absorption edge indicates the optical homogeneity of the deposited films. Using the measured values $\mathrm{T}$ and $\mathrm{R}$, the absorption coefficient $\alpha$ was calculated from [15]

$$
\alpha=\frac{1}{d} \ln \left[\frac{(1-R)^{2}}{2 T}+\left(\frac{(1-R)^{4}}{4 T^{2}}+R^{2}\right)^{1 / 2}\right]
$$

where $d$ is the film thickness. The direct energy gap were extracted from

$$
\alpha=\frac{A}{h v} \sqrt{h v-E_{g}}
$$

by plotting $\mathrm{h}$ (photon energy) on $\mathrm{x}$-axis and $(\alpha \mathrm{h} U)^{2}$ on $\mathrm{y}$-axis as in Fig. (10). The values of the energy gab with sample preparation condition are given in Table (1). The values of the energy gap ranged from 1.50 to $1.65 \mathrm{eV}$ in agreement with that of CdTe polycrystalline material [16].

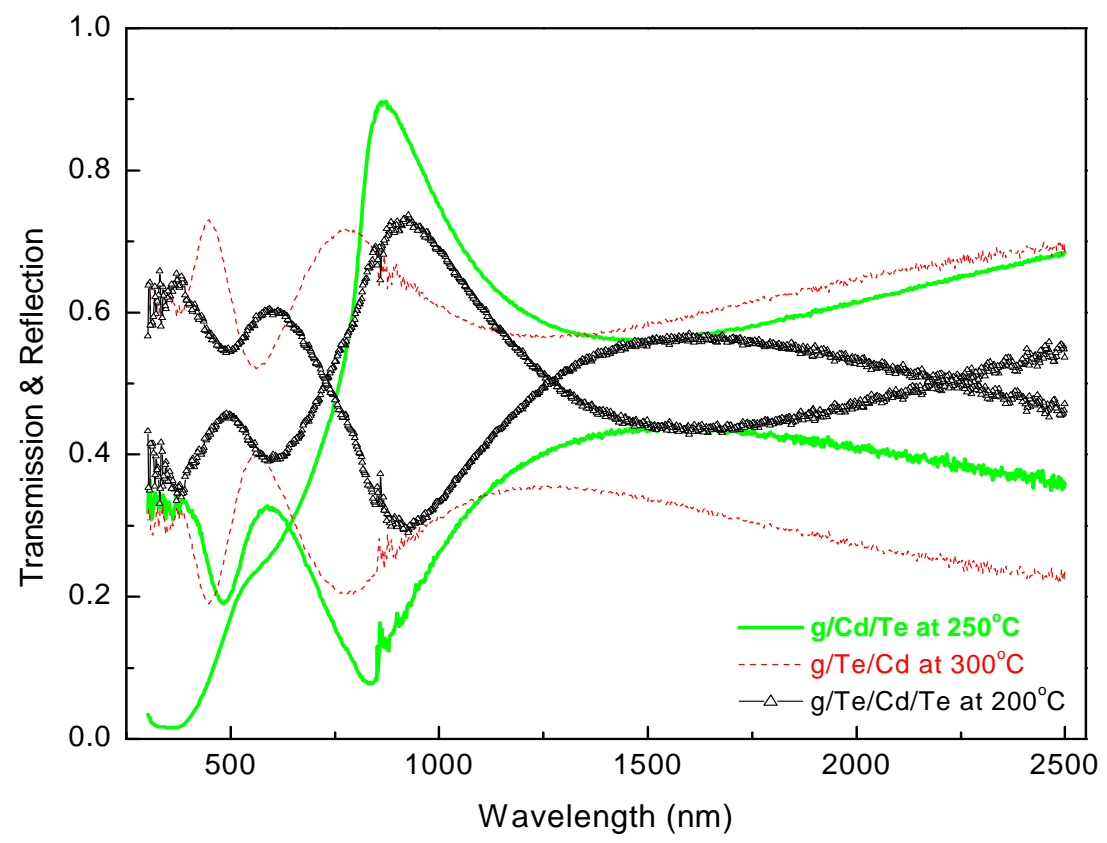

Fig.(9): Transmittance and reflectance spectra for the best sample of each of the three sequences (preparation conditions are indicated). 


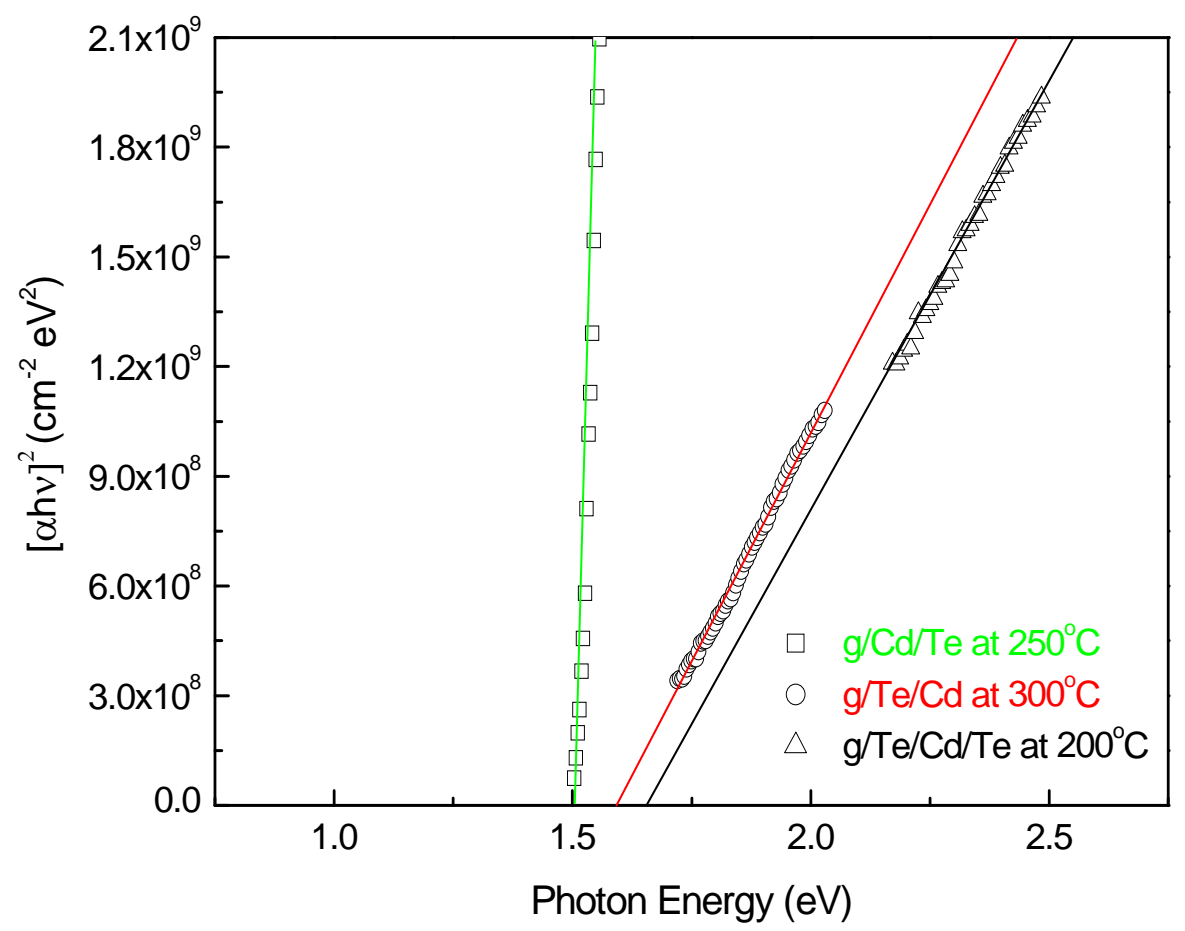

Fig.(10): $(\alpha h v)^{2}$ versus $h v$ for the best sample of each of the three sequences (preparation conditions are indicated).

Table (1): Optical gap for polycrystalline CdTe thin films.

\begin{tabular}{||c||c|c||}
\hline Layer sequence & $\begin{array}{c}\text { Annealing } \\
\text { temperature }\left({ }^{\circ} \mathrm{C}\right)\end{array}$ & Energy gap $(\mathrm{eV})$ \\
\hline \hline $\mathrm{g} / \mathrm{Cd} / \mathrm{Te}$ & 250 & 1.50 \\
\hline $\mathrm{g} / \mathrm{Te} / \mathrm{Cd}$ & 300 & 1.59 \\
\hline $\mathrm{g} / \mathrm{Te} / \mathrm{Cd} / \mathrm{Te}$ & 200 & 1.65 \\
\hline
\end{tabular}

\section{Conclusions:}

Different sequences of $\mathrm{Cd}$ and $\mathrm{Te}$ stacked elemental layers can form polycrystalline CdTe thin films under the effect of annealing at different temperatures even in air. X-ray diffraction analysis used to characterize all prepared films indicates that the best condition is sequence of glass $/ \mathrm{Te} / \mathrm{Cd} / \mathrm{Te}$ and annealing at $200^{\circ} \mathrm{C}$ for 30 minutes. Average crystallite size of $9.4 \mathrm{~nm}$ with no grains exceed $30 \mathrm{~nm}$ in nanoscale range can be achieved. Values of the optical gap (1.5-1.65 eV) verify the formation of polycrystalline CdTe thin films using the stacked elemental layer with a proper heat treatment. 


\section{References:}

1. M. B. Das, S. V. Krishnaswamy, R. Petkie, P. Swab, K. Vams, Soild State Electron, 27, 329 (1984).

2. M. P. R. Panicker, M. Knaster, F. A. Kroger, J. Electrochem. Soc., 125, 556 (1978).

3. H. Uda, H. Taniguchi, M. Yoshida, Y. Yamashita, Jpn. J. Appl. Phys., 17, 585 (1978).

4. J. Ramiro, A. Perea, J. F. Trigo, Y. Laaziz, E. G. Camarero, Thin Solid Films, 361-362, 65 (2000)

5. F. Jackson, L. E. A. Berlouis, P. Rocabois, B. C. Cavenett, J. Cryst. Growth, 159, 200 (1996).

6. Giardini, M. Ambrico, D. Smaldone, R. Martino, G. P. Parisi, V. Capozzi, G. Perna, Appl. Surf. Sci., 106, 144 (1996).

7. J. T. Cheung, M. Khoshnevisan, T. Magee, Appl. Phys. Lett., 43, 462 (1983).

8. R. M. Alamoud, Eng. Sci. 2 , 211 (2002)

9. Ashour, A. A.Ramadana, K. Abd EL-Hady, A. A. S. Akl, Journal of Optoelectronics and Advanced Materials, 7 (3), 1493 (2005).

10. M. T. Bhatti, K. M. Hynes, R. W. Miles, R. Hill, Int. J. Solar Energy, 12, 171 (1992).

11. R. W. Miles, M. T. Bhatti, K. M. Hynes, A. E. Baumann, R. Hill, Mater. Sci. Eng., B16, 250 (1993).

12. L. R. Cruz, R. R. de Avillez, Thin Solid Films, 373, 15 (2000).

13. S. Krumn; XIII th Conference on Clay Mineralogy and Petrology, Praha (1994), Acta Universitatis Carolinae Geologica, 38, 253 (1994).

14. K. El-Zawawi and A. M. El-Shabiny, Egypt. J. Solids., 27 (2), 223, (2004)

15. R. E. Denton, R. D. Cambell and S. G. Tpmlin, J. Phys. D 5, 852, (1972)

16. A. Abd El-Mongy, A. A. Ramadan, and H. M. Hashem, phys. stat. sol. (a), 202 (10), 1925 (2005). 